\title{
Dynamic affordability assessment: predicting an applicant's ability to repay over the life of the loan
}

\author{
Katarzyna Bijak \\ Southampton Management School, University of Southampton, Highfield, \\ Southampton SO17 1BJ, UK; email: k.bijak@soton.ac.uk
}

\section{Lyn C. Thomas}

Southampton Management School, University of Southampton, Highfield, Southampton S017 1BJ, UK; email: I.thomas@soton.ac.uk

\section{Christophe Mues}

Southampton Management School, University of Southampton, Highfield, Southampton SO17 1BJ, UK; email: c.mues@soton.ac.uk

(Received February 27, 2013; revised February 13, 2014; accepted February 14, 2014)

In the credit decision-making process, both an applicant's creditworthiness and their affordability should be assessed. While credit scoring focuses on creditworthiness, affordability is often checked on the basis of current income and estimated current consumption as well as existing debts stated in a credit report. Contrary to that static approach, a theoretical framework for dynamic affordability assessment is proposed in this paper. In this approach, both income and consumption are allowed to vary over time and their changes are described with random effects models for panel data. The models are derived from the economic literature, including the Euler equation of consumption. A simulation is run on their basis and predicted time series are generated for a given applicant. For each pair of the predicted income and consumption time series, the applicant's ability to repay is checked over the life of the loan, for all possible installment amounts. As a result, a probability of default is assigned to each amount, which can help find the maximum affordable installment. This is illustrated with an example based on artificial data. Assessing affordability over the loan repayment period as well as taking into account variability of income and expenditure over time are in line with recommendations of the UK Office of Fair Trading and the Financial Services Authority. In practice, the suggested approach could contribute to responsible lending.

The authors are grateful to the anonymous referees for their valuable comments and suggestions. 


\section{INTRODUCTION}

Credit scoring focuses on creditworthiness, ie, an applicant's propensity to repay a loan. However, even high creditworthiness does not necessarily mean the ability to repay. Therefore, affordability should also be assessed. In many countries, regulations put affordability assessment at the center of responsible lending. A loan can be considered affordable

if its level and terms allow the consumer to meet current and future payment obligations in full, without recourse to further debt relief or rescheduling, avoiding accumulation of arrears while allowing an acceptable level of consumption.

Financial Services Authority (2010, Paragraph 2.16)

Thus, affordability assessment can be defined as

a 'borrower-focussed test' which involves a creditor assessing a borrower's ability to undertake a specific credit commitment, or specific additional credit commitment, in a sustainable manner, without the borrower incurring (further) financial difficulties and/or experiencing adverse consequences.

Office of Fair Trading (2011, Paragraph 4.1)

There is some similarity between assessing affordability and estimating the probability of default (PD), since both focus on a possible repayment (or lack thereof). Nevertheless, the former concentrates only on the lack of repayment as a result of the borrower's inability to repay, whereas the latter does not differentiate between the reasons for default. Moreover, when assessing affordability we should analyze whether the credit commitment can be met "in a sustainable manner", and when estimating PD we just predict whether it will be met, no matter how. This is a crucial issue in responsible lending.

There is little literature on statistical models and methods for affordability assessment. Finlay (2006) proposed a linear regression model to estimate the expenditure-toincome ratio for such purposes and a logistic regression model to estimate probability of overindebtedness, both based on application data and credit reports. However, in the conclusions to his paper, the dynamic nature of income and expenditure is mentioned as a possible argument against the use of those static models. On the other hand, Thomas (2009) presented a rough idea of structural models based on affordability, where default is a result of cashflow problems. Although it was suggested with a view to modeling the credit risk of portfolios of consumer loans, it could also be applied for assessing affordability. In that approach, the asset process is modeled. Each month, the consumer's realizable assets are increased by their income and reduced by both expenditure and loan repayment. Once realizable assets become negative or fall below a percentage of the total debts, the consumer defaults. The dynamics of the asset process could be modeled by treating income and expenditure as functions of 
economic conditions. In this research, the above-mentioned general idea, with some modifications, has been developed into a complete theoretical framework.

Introducing dynamics into consumer risk models is one of the current challenges in credit scoring (Crook and Bellotti 2008; Thomas 2011). As far as affordability assessment is concerned, both the UK's Office of Fair Trading (OFT) and the Financial Services Authority (FSA $)^{1}$ recommend taking a long-term perspective and considering future changes in the applicant's income and expenditure. In practice, though, a static approach is often used, based on current income and estimated current consumption as well as existing debts reported by credit reference agencies. Such an approach assumes that the customer's financial situation will stay the same in the future. Consequently, it is likely to underestimate possible increase in consumption, which may lead to granting too much credit, overindebtedness and default. On the other hand, if a possible increase in income is underestimated, the customer may be offered less credit than they would be able to repay, and thus the lender will lose potential profits. In contrast to that static approach, this paper proposes dynamic affordability assessment.

In this research, affordability is measured by a function that assigns to each possible installment amount a probability of the applicant defaulting over the loan repayment period. Consequently, affordability assessment means estimation of this function. It is assumed that the customer's income and consumption vary over time. Changes in income and consumption are modeled with random effects models for panel data (time-series cross-sections). The model formulas are derived from the economic literature. Consumption is described with a log-linearized version of the Euler equation. The estimated models are then applied in a simulation that is run for the applicant. In each iteration, the predicted income and consumption time series are generated, and the customer's ability to repay is assessed over the life of the loan, for all possible installment amounts. As a result, each amount can be assigned with a probability of the event of interest (be it default or just failure to pay) over any time period. In particular, affordability can be assessed and the maximum affordable installment can be identified. The design of this approach is such that a loan is affordable if the applicant is able to repay it while also meeting consumption costs and repayments of all other debts month after month until the loan is paid in full, which is in line with the guidelines of the Office of Fair Trading (2011) and the suggestions of the Financial Services Authority (2010). The proposed approach is illustrated with an example based on artificial data.

The paper is structured as follows. Section 2 is on the research background that covers overindebtedness, codes of practice and guidelines on responsible lending as

\footnotetext{
${ }^{1}$ The FSA ceased to exist in 2013 and most of its responsibilities were transferred to two new authorities: the Prudential Regulation Authority (PRA), which is a part of the Bank of England, and the Financial Conduct Authority (FCA).
} 
well as affordability assessment solutions used in banking practice. In Section 3, the methodology (income and consumption change models, simulation design, affordability assessment) is described. In Section 4, an example based on artificial data is presented. Section 5 is a discussion on what data would be needed to apply this theoretical framework in practice. Section 6 includes a summary and conclusions.

\section{BACKGROUND}

\subsection{Overindebtedness}

Affordability assessment is inextricably linked to the concepts of consumer overindebtedness and responsible lending. Irresponsible lending practices are blamed for exacerbating overindebtedness (Kempson 2002). In particular, increasing the credit limit or granting credit without reasonable affordability assessment may lead to the customer being overindebted, which often ends in default. The financial crisis raised interest in overindebtedness across Europe (Fondeville et al 2010). In the UK, the scale and drivers of this phenomenon have been intensively studied for over ten years (see Kempson 2002; Oxera 2004; Disney et al 2008; Bryan et al 2010).

There are many definitions of overindebtedness, eg, "the circumstance where the household's credit-financed spending plans are inconsistent with its potential income stream" (Disney et al 2008). According to Betti et al (2001), there are three models (types of definitions) of overindebtedness: administrative, subjective and objective (quantitative). Under the administrative model, overindebtedness occurs when it is declared before the court or registered by an official authority. The subjective model assumes that the overindebted are those who self-define themselves as overindebted. Under the objective model, overindebtedness is assessed using such measures as the debt-service-to-income ratio. Using a mix of the latter two models, the Department of Trade and Industry (2005) listed the following indicators of overindebtedness:

- spending more than $25 \%$ of gross income on repayments of unsecured loans;

- spending more than $50 \%$ of gross income on repayments of both secured and unsecured loans;

- having four or more credit commitments;

- being in arrears for more than three months and considering repayments "a heavy burden".

However, Betti et al (2001) were critical of applying the same overindebtedness thresholds to all customers, no matter what stage of life they are in. For example, young persons, whose incomes are likely to increase over time, can cope with higher debt-toincome ratios than older persons. Therefore, Betti et al suggested taking into account 
not only the customer's current income but also their permanent income, ie, expected income over a long period of time, as defined by Friedman (1957). According to the permanent income hypothesis (PIH), current consumption depends on permanent rather than current income and is sensitive to permanent but not transitory income shocks (Snowdon and Vane 2005). As well as using the PIH, Betti et al proposed applying the life-cycle theory (Modigliani and Brumberg 1954). According to this theory, consumers smooth their consumption over time, eg, young persons may borrow against their expected future incomes. These suggestions, repeated by Disney et al (2008), are in favor of a dynamic approach to affordability assessment.

\subsection{Responsible lending}

Affordability assessment is considered the main component of responsible lending, ie, "acceptable practices that ensure borrowers can afford the repayments and know the consequences, and still try to accommodate as many people as possible" (Anderson 2007, p. 627). Consequently, disregarding the significance of affordability assessment is one of the features of irresponsible (reckless) lending. The Consumer Credit Directive states that "it is important that creditors should not engage in irresponsible lending" (European Parliament and Council of the European Union 2008, Point 26). Irresponsible lending is a worldwide problem, and there have been some legislative attempts to tackle it in many countries (the 2010 Dodd-Frank Wall Street Reform and Consumer Protection Act in the US, the National Consumer Credit Protection Act 2009 in Australia and the National Credit Act 2005 in South Africa, for example).

Examples of irresponsible lending practices include (Office of Fair Trading 2011):

- lack of policies and procedures for reasonable affordability assessment;

- lack of affordability assessment in individual cases;

- failure to assess whether an applicant is likely to be able to repay in a sustainable manner;

- granting credit without having assessed affordability or when the affordability assessment results suggest that the credit is likely to be unsustainable.

In the UK, such practices may even lead to revoking a consumer credit licence, since the Consumer Credit Act 2006 (Section 29, Subsection 2) states that the practices which look to the OFT as involving irresponsible lending are taken into account when considering the creditor's fitness to hold the licence.

According to the best practice set out in the "Guide to Credit Scoring", banks should assure applicants that "as responsible lenders, we take into account your personal circumstances to establish the appropriate level of credit to grant to you" (Association 
for Payment Clearing Services et al 2000, Appendix 2). In line with the Lending Code, which sets more standards of good practice for UK banks, "before lending any money, granting or increasing an overdraft or other borrowing, subscribers should assess whether the customer will be able to repay it in a sustainable manner" (British Bankers' Association et al 2011, Section 4, Paragraph 50) and "before giving a customer a credit limit, or increasing an existing limit, subscribers should assess whether they feel the customer will be able to repay it" (British Bankers' Association et al 2011, Section 6, Paragraph 115). Moreover, "issuers should undertake appropriate checks to assess a customer's ability to repay... before increasing a credit limit" (UK Cards Association 2011, Section 2.4).

The OFT suggested that lenders use various sources of information to assess affordability, eg, evidence of income and expenditure and/or credit reports provided by credit reference agencies. If income or expenditure is used, both the applicant's current situation and the expected future changes over the life of the loan should be taken into account. Generally, lenders are encouraged to view credit sustainability in a longterm perspective: they can accept occasional missing of a payment on a due date or

- in some circumstances - even temporary (initial) inability to repay (Office of Fair Trading 2011, Paragraphs 4.7 and 4.9).

As far as mortgages are concerned, the FSA proposed that lenders take into account the applicant's income, expenditure and debts and calculate their free disposable income in order to assess affordability. They should use statistical data to estimate expenditure. Furthermore, lenders should assess the applicant's ability to repay over the loan repayment period, considering variability of income over time (Financial Services Authority 2010). However, these FSA suggestions were only put in a consultation paper and thus are not binding for banks.

To sum up, there are some codes of practice and guidelines on responsible lending, including affordability assessment, but they are rather general and do not advocate any specific statistical models or methods. Nevertheless, it is worth noting that both the OFT and FSA recommend taking a long-term perspective and considering future changes in the applicant's income and expenditure.

\subsection{Banking practice}

In the industry, there are concerns that if responsible lending criteria are too strict, the existing business model may not be sustainable anymore (Wilkinson 2007). There are also concerns that such criteria may limit consumer access to bank credit and, as a result, banks may lose their customers to nonbanking financial companies that are not subject to any regulations on responsible lending. However, lending to those who can be reasonably identified as unlikely to repay is neither ethical nor profitable 
(although it can be part of a generally profitable, yet still unethical, business model). Therefore, accurate affordability assessment is important.

The affordability measure which is widely used in banking is the debt-service-toincome ratio, the same ratio as that used to assess overindebtedness. The debt-serviceto-income ratio can also be computed using application data, information on the applicant's credit commitments from credit reference agencies and their expenditure estimate, where expenditure is modeled on public data (Lucas 2005). After taking into account the new installment, this ratio can be compared with a threshold (cutoff) in order to assess affordability. Generally, approaches to affordability assessment are often based on information from the above-mentioned three sources: application data (including income), credit reports and estimation of expenditure. This allows disposable income to be calculated (Dell 2007; Maydon 2011). The result can then be compared with the new installment in the credit decision-making process.

There are two approaches to affordability assessment for mortgages: income multiples and affordability models (Financial Services Authority 2009). The former are fixed and can only vary between groups of applicants; this is a "one-size-fits-all" approach. The latter use estimates of the applicant's income and expenditure to calculate their maximum affordable loan amount. Various methods are applied and the models differ in their complexity level. Large lenders use affordability models more often than small lenders (Financial Services Authority 2009). These have a clear advantage over income multiples, as they are based not only on income but also on expenditure. Thus, it is not surprising that they have become more and more popular (Financial Services Authority 2009).

As far as credit cards are concerned, an affordability model can be applied to assess the impact of changes in credit limit on the customer's risk profile. For example, Somers (2009) built a model for Lloyds Banking Group that estimates the probability of the customer being "bad" (ie, defaulting). This stepwise regression model takes into account the forecasted limit that is estimated using another model with a risk score as the only variable. In the affordability model, the following variables are used: a risk score, the log ratio of the actual limit and the forecasted limit, as well as a number of characteristics multiplied by this log ratio. The latter are added to adjust the model outcome, especially for those customers where the forecasted limit differs substantially from the actual one. This is part of a solution designed to determine new credit limits.

Since it is impossible to assess affordability without information on the applicant's debts, credit reference agencies seem a natural place to develop solutions that are dedicated to affordability assessment. An example of such a solution is Experian's Affordability Index (Experian 2011). It is a multi-scorecard model where the customer's status definition is based not only on their delinquencies but also on the Consumer Indebtedness Index. Factors that indicate a high indebtedness level include excessive 
credit activity and high credit card utilization rates. When assessing affordability, Experian takes into account (among other things) the applicant's socio-demographic characteristics, income and credit commitments as well as their expenditure estimated using the Office for National Statistics (ONS) Expenditure and Food Survey (EFS) data (Russell 2005; Brooksby 2009). Another example is Callcredit's Affordability Suite, which includes such tools as indicators based on debt to income ratios and a score to assess probability of default as a result of overindebtedness. ${ }^{2}$

It is difficult to conclude much about the affordability models observed by the Financial Services Authority (2009), since their details are not publicly available. Most of the other above-mentioned solutions, which are applied in banking, use at least some of the sources of information suggested by the OFT. Nevertheless, these approaches are static and, as far as it can be ascertained, none of them directly implement the OFT and FSA recommendations to assess the ability to repay over the life of the loan, taking into account variability of income and expenditure over time.

\section{METHODOLOGY}

\subsection{Income change model}

In this research, the proposed approach to affordability assessment is based on income and consumption models. There is much economic literature on modeling these quantities at the individual or household level; to mention just one example, Miles (1997) estimated income and consumption regressions. This section and the next focus only on those models that are designed for panel data. Such models are less commonly used than models for cross-sectional data because of their higher complexity and lower availability of suitable data sets. However, panel data models have the advantage of not ignoring the fact that things change over time.

As far as income is concerned, net labor income is usually modeled. Similar models have been built at both the household level (see, for example, Guiso et al 1992; Jappelli and Pistaferri 2006) and the individual level (see, for example, Auten and Carroll 1999; Koskinen et al 2007). If household income is modeled, characteristics of the head of household are taken into account as well as family size or number of earners. Regardless of the modeling level (individual/household), similar regressors are included both where income is the dependent variable (see, for example, Lillard and Willis 1978; Guiso et al 1992; Etienne 2006) and where income change is the dependent variable (see, for example, Lusardi 1992; Auten and Carroll 1999; Jappelli and Pistaferri 2006). Either the individual's characteristics or their changes can be used as regressors to model income change. Using the characteristics reflects the belief

${ }^{2}$ See "The Affordability Suite - Calculate Your Customer's Risk and Affordability". URL: www .callcredit.co.uk/products-and-services/credit-risk-and-affordability/the-affordability-suite.

Journal of Credit Risk 10(1) 
TABLE 1 Income determinants in selected models.

\begin{tabular}{lccccc}
\hline \multicolumn{1}{c}{ Income model } & $\begin{array}{c}\text { Education } \\
\text { level }\end{array}$ & Occupation & Region & Age & Sex \\
\hline Auten and Carroll (1999) & & $\checkmark$ & $\checkmark$ & $\checkmark$ & \\
Etienne (2006) & $\checkmark$ & $\checkmark$ & & $\checkmark$ & \\
Guiso et al (1992) & $\checkmark$ & $\checkmark$ & $\checkmark$ & $\checkmark$ & $\checkmark$ \\
Jappelli and Pistaferri (2006) & $\checkmark$ & & $\checkmark$ & $\checkmark$ & $\checkmark$ \\
Lillard and Willis (1978) & $\checkmark$ & & $\checkmark$ & & \\
Lusardi (1992) & $\checkmark$ & $\checkmark$ & & & $\checkmark$ \\
\hline
\end{tabular}

that the relationship between them and income may vary over time, eg, earnings of more educated workers are likely to grow faster than earnings of less educated workers (Auten and Carroll 1999). No matter how income is modeled, since its distribution tends to be right-skewed, the log transformation is often performed to eliminate the skewness (see, for example, Lusardi 1992; Etienne 2006; Jappelli and Pistaferri 2006).

In income models, the following characteristics are most frequently used: education level, occupation, region, age and sex (see Table 1). Among other income determinants that are included in the models are the sector of occupation (see, for example, Guiso et al 1992) and year of birth (see, for example, Etienne 2006). The latter is used to control for the cohort effect. If we believe that younger generations are always better off than older ones and this relationship is linear, year of birth can be directly implemented in the model. Otherwise, we can consider its polynomial, like Etienne (2006), or a set of dummy variables, eg, to indicate those cohorts who entered the labor market in recessions, since this might negatively affect their income for a long time. Obviously, the other above-mentioned variables, except for age, are coded as sets of dummies. Instead of age, we can use its polynomial (see, for example, Etienne 2006; Jappelli and Pistaferri 2006).

Although macroeconomic variables such as GDP can be explicitly included in income models (see, for example, Koskinen et al 2007), macroeconomic conditions (referred to as "aggregate shocks" in the economics literature) are often taken into account by using fixed time effects in the form of time dummies (see, for example, Lillard and Willis 1978; Lusardi 1992; Jappelli and Pistaferri 2006). Time dummies can capture the combined effect of macroeconomic variables that are not used as regressors in the model (Lillard and Willis 1978). Thus, time effects describe the macroeconomic environment as a whole and not only its selected elements, such as production or unemployment. In panel data models we can also implement random time effects, but this requires data covering long time periods and thus random time effects are rarely used. They are normally operationalized by using time dummies. 
In income models for panel data, individual effects are components that are specific to households or individuals and are constant over time. In fixed effects (FE) models, individual effects are estimated along with the other parameters (see, for example, Etienne 2006), whereas in random effects (RE) models individual effects are part of the error term (see, for example, Lillard and Willis 1978). The original formula for an RE model, which was developed by Balestra and Nerlove (1966), also included a random time-specific component, but usually this component is either omitted or replaced. Since fixed effects control for all permanent characteristics, only timevariant regressors can be included in FE models unless a more complicated estimator, such as the Hausman-Taylor estimator, is used (Verbeek 2004). Another disadvantage of FE models is that they cannot be applied to predict for individuals or households outside the training sample unless their unknown individual effects are assumed to be equal to zero or, for example, to the training sample mean. If individual effects are assumed to be related to income and not to its change, they can be removed from the model by first-differencing and, as a result, they can be absent in income change models (Auten and Carroll 1999). Such a transformation potentially allows for using the first-difference (FD) estimator that is a more convenient estimation method (Wooldridge 2010). However, first-differencing also eliminates time-invariant regressors from the model and in practice it would rule out most characteristics. Thus, an RE model is more suitable to predict income change.

When assessing affordability, the applicant's current income is known. Starting with this initial value, their income in consecutive months can be predicted using an income change model. Taking into account all the above considerations, the following $\mathrm{RE}$ model is proposed for the purposes of this research:

$$
\begin{aligned}
\Delta \ln Y_{i t+1}=\alpha_{0} & +\alpha_{1} \text { age }_{i t}+\alpha_{2} \text { cohort }_{i}+\alpha_{3} \text { sex }_{i}+\alpha_{4} \text { education }_{i} \\
& +\alpha_{5} \text { occupation }_{i}+\alpha_{6} \text { sector }_{i}+\alpha_{7} \text { region }_{i}+\mu_{i}+\eta_{t+1}+\varepsilon_{i t+1},
\end{aligned}
$$

which, after operationalizing random time effects $\eta_{t+1}$ as time dummies $D_{t+1}^{(s)}$, gives

$$
\begin{aligned}
\Delta \ln Y_{i t+1}=\sum_{s=1}^{T-1} \gamma_{s} D_{t+1}^{(s)} & +\alpha_{0}+\alpha_{1} \text { age }_{i t}+\alpha_{2} \text { cohort }_{i}+\alpha_{3} \operatorname{sex}_{i}+\alpha_{4} \text { education }_{i} \\
& +\alpha_{5} \text { occupation }_{i}+\alpha_{6} \text { sector }_{i}+\alpha_{7} \text { region }_{i}+\mu_{i}+\varepsilon_{i t+1},
\end{aligned}
$$

where $Y_{i t+1}$ is the $i$ th customer's income in month $t+1$ and age ${ }_{i t}$ represents their age in month $t$. The other characteristics are assumed to be constant, as they typically remain relatively time-invariant. Sex is included since, "after discussion with industry experts", Finlay (2006) came to the conclusion that it may be allowed in affordability models, although its use is debatable. If $T$ denotes the number of months in the training 
sample, there are $T-1$ time dummies $D_{t+1}^{(1)}, \ldots, D_{t+1}^{(T-1)}$ such that $D_{t+1}^{(s)}=1$ if $s=t+1$ and $D_{t+1}^{(s)}=0$ otherwise.

In this model, the error term is the sum of the random individual effect $\mu_{i}$ and an idiosyncratic component $\varepsilon_{i t+1}$. Using an RE model requires adopting some assumptions on the error term elements (Greene 2000): $\mu_{i}$ and $\varepsilon_{i t}$ are orthogonal and both of them are white noise, ie, they have zero means and are spherical (homoscedastic and not serially correlated). Due to the presence of the random individual effect, there is autocorrelation of the error term, and thus the generalized least squares (GLS) estimator is recommended. For more details on RE models and their estimation, the reader can refer to the appropriate chapters in general econometrics textbooks (see, for example, Greene 2000; Maddala 2001; Verbeek 2004) or the panel data literature such as Wooldridge (2010). RE models can be estimated using popular statistical software packages such as SAS or STATA.

\subsection{Consumption change model}

Consumption is usually modeled using Euler equations. The Euler equation of consumption, ie, an intertemporal first-order condition for the consumer's optimization problem, was first used by Hall (1978), who proposed a random walk model inspired by the Lucas (1976) critique. The Euler equation and its log-linearized version presented below have been partly motivated by those applied by Zeldes (1989), Runkle (1991) and Lusardi (1992). In this approach, the $i$ th consumer has a constant relative risk aversion utility function,

$$
U\left(C_{i t}, \theta_{i t}\right)=\frac{C_{i t}^{1-a}}{1-a} \exp \left(\theta_{i t}\right)
$$

where $C_{i t}$ is their consumption at time $t, a$ is the Arrow-Pratt measure of relative risk aversion and $\theta_{i t}$ represents factors that shift the consumer's tastes. These factors include age (expressed in the same units as $t$ ) and other characteristics represented here by the generic variable $X_{i t}$. They also contain a consumer-specific component $b_{i}$, a time-specific component $b_{t}$ and an idiosyncratic component $b_{i t}$ that is orthogonal to both $b_{i}$ and $b_{t}$ (it is also assumed that all components have zero means):

$$
\theta_{i t}=b_{0} \text { age }_{i t}+b_{1} \text { age }_{i t}^{2}+b_{3} X_{i t}+b_{i}+b_{t}+b_{i t} .
$$

The Euler equation is an equilibrium condition. If the consumer makes optimal consumption choices, then their current marginal utility is equal to the present value of the expected future marginal utility corrected for their time preference rate:

$$
U^{\prime}\left(C_{i t}, \theta_{i t}\right)=E_{t}\left[\frac{U^{\prime}\left(C_{i t+1}, \theta_{i t+1}\right)\left(1+r_{i}\right)}{\left(1+d_{i}\right)}\right]
$$


where $U^{\prime}$ is the derivative of $U$ with respect to the consumption; $r_{i}$ and $d_{i}$ are the interest rate and the time preference (discount) rate, respectively (in this version of the Euler equation, the interest rate is constant over time but may vary between consumers). The ratio of the marginal utilities corrected for $r_{i}$ and $d_{i}$ is equal to 1 plus the expectation error $e_{i t+1}$ :

$$
\frac{U^{\prime}\left(C_{i t+1}, \theta_{i t+1}\right)\left(1+r_{i}\right)}{U^{\prime}\left(C_{i t}, \theta_{i t}\right)\left(1+d_{i}\right)}=1+e_{i t+1} .
$$

The expectation error has zero mean and variance $\sigma_{e}^{2}$. The relationship between the interest rate and the time preference rate shapes the individual's consumption path over time. If $r_{i}$ and $d_{i}$ are assumed to be equal, they eliminate each other from the equation (see Lusardi 1992). In this research, a more general assumption is adopted. Since both $r_{i}$ and $d_{i}$ are consumer-specific, their relationship is also specific to the consumer:

$$
\frac{1+r_{i}}{1+d_{i}}=1+\frac{r_{i}-d_{i}}{1+d_{i}}=1+z_{i}
$$

The mean of $z_{i}$ equals 0 and its variance is $\sigma_{z}^{2}$. Moreover, $z_{i}$ and $b_{i t}$ are independent and so are $z_{i}$ and $e_{i t}$. The formula for the marginal utilities ratio is linearized by taking $\operatorname{logs}$. The second-order Taylor approximation of a function $\ln (1+x)$ is given by

$$
\ln (1+x) \cong x-\frac{1}{2} x^{2}
$$

Using such approximations of $\ln \left(1+z_{i}\right)$ and $\ln \left(1+e_{i t+1}\right)$ results in the following consumption change model:

$$
\Delta \ln C_{i t+1}=\beta_{0}+\beta_{1} \text { age }_{i t}+\beta_{2} \Delta X_{i t+1}+v_{i}+\lambda_{t+1}+\zeta_{i t+1},
$$

where

$$
\beta_{0}=\frac{1}{a}\left(b_{0}+b_{1}-\frac{\sigma_{z}^{2}}{2}+\frac{\sigma_{e}^{2}}{2}\right), \quad \beta_{1}=\frac{2 b_{1}}{a}, \quad \beta_{2}=\frac{b_{2}}{a} .
$$

In this model, the error term is the sum of the individual effect

$$
v_{i}=\frac{1}{a}\left[\left(z_{i}-\frac{z_{i}^{2}}{2}\right)+\frac{\sigma_{z}^{2}}{2}\right]
$$

the time effect

$$
\lambda_{t+1}=\frac{b_{t+1}-b_{t}}{a}
$$


and an idiosyncratic component

$$
\zeta_{i t+1}=\frac{1}{a}\left[\left(b_{i t+1}-b_{i t}\right)-\left(e_{i t+1}-\frac{e_{i t+1}^{2}}{2}\right)-\frac{\sigma_{e}^{2}}{2}\right] .
$$

The original consumer-specific component $b_{i}$ has been ruled out from the model by taking differences. In order to make the means of the error term elements equal zero, $\sigma_{z}^{2} / 2 a$ and $-\sigma_{e}^{2} / 2 a$ have been added to $v_{i}$ and $\zeta_{i t+1}$, respectively, and then subtracted from the intercept $\beta_{0}$.

In such models, nondurable consumption change is usually modeled. However, nondurable consumption is often limited to food expenditure because of data availability (see Hall and Mishkin 1982). Traditionally, the Euler equation does not differentiate between essential consumption (eg, groceries) and so-called quality of life consumption (eg, meals out). Although it was originally formulated at the individual level, most models are developed at the household level, since household surveys are the main source of panel data on consumption. The model built by Finlay (2006) to estimate the expenditure-to-income ratio is also at the household level. Nevertheless, a loan application (including affordability) is usually assessed at the individual level (unless it is a joint application). Therefore, the models proposed in this paper are at the individual level as well.

There are only a few characteristics that are typically used in consumption change models: age of the head of household, change in the number of children and change in the number of adults or in the family size (see Hall and Mishkin 1982; Zeldes 1989; Lusardi 1992; Jappelli and Pistaferri 2000). Instead of age, its polynomial can be implemented (see, for example, Hall and Mishkin 1982). Instead of the total number of children, we could consider the number of children in different age groups, since they have different consumption needs. Other variables, such as income change, are added to test economic hypotheses. However, income variables turn out to be insignificant in some consumption change models, which suggests that current consumption does not depend on current income and thus supports the PIH (see, for example, Runkle 1991). As in income models, aggregate shocks are often taken into account by using fixed time effects in the form of time dummies (see, for example, Zeldes 1989; Lusardi 1992). Individual effects are sometimes also included: for example, Zeldes (1989) incorporated household-specific components as fixed effects into a consumption change model.

Since FE models cannot be applied to predict outside the training sample without additional assumptions, an RE model of consumption change is proposed for the purposes of this research:

$$
\begin{aligned}
\Delta \ln C_{i t+1}=\beta_{0}+\beta_{1} \operatorname{age}_{i t}+\beta_{2} \Delta \text { children }_{i t+1}^{(0-3)}+\beta_{3} \Delta \text { children }_{i t+1}^{(4-15)} & \\
& +\beta_{4} \Delta \text { children }_{i t+1}^{(16-19)}+v_{i}+\lambda_{t+1}+\zeta_{i t+1} .
\end{aligned}
$$


This can be operationalized by replacing random time effects $\lambda_{t+1}$ with time dummies:

$$
\begin{aligned}
\Delta \ln C_{i t+1}=\sum_{s=1}^{T-1} \delta_{s} D_{t+1}^{(s)}+\beta_{0}+\beta_{1} \operatorname{age}_{i t}+\beta_{2} \Delta \operatorname{children}_{i t+1}^{(0-3)} & \\
& \quad+\beta_{3} \operatorname{children}_{i t+1}^{(4-15)}+\beta_{4} \Delta \operatorname{children}_{i t+1}^{(16-19)}+v_{i}+\zeta_{i t+1},
\end{aligned}
$$

where $C_{i t+1}$ is the $i$ th customer's consumption in month $t+1$ and, for example, children $_{i t+1}^{(0-3)}$ represents the number of children aged zero to three years old. As far as the error term elements are concerned, the same assumptions are adopted on them as on $\mu_{i}$ and $\varepsilon_{i t}$ in the income change model: $v_{i}$ and $\zeta_{i t}$ are orthogonal and both of them are white noise.

The income and consumption change models should be estimated on a training sample and tested/validated on a hold-out sample. The results will contain estimates of the model parameters $(\hat{\boldsymbol{\alpha}}, \hat{\boldsymbol{\beta}}, \hat{\boldsymbol{\gamma}}, \hat{\boldsymbol{\delta}})$ as well as variances of the random individual effects $\left(\hat{\sigma}_{\mu}^{2}, \hat{\sigma}_{v}^{2}\right)$ and the idiosyncratic components $\left(\hat{\sigma}_{\varepsilon}^{2}, \hat{\sigma}_{\zeta}^{2}\right)$. The final models may differ slightly from those proposed, since any variables that turn out to be insignificant should be removed from the equations.

\subsection{Simulation}

In this paper, the applicant's ability to repay is assessed on the basis of their predicted income and consumption in the repayment period. Once the models are fitted, these future quantities can be estimated for any applicant whose current income and expenditure are known (eg, stated in the loan application). It is not clear, though, what values should be assigned to the individual effects and which time dummies should be selected for future months. Therefore, a simulation is run to take into account the random components (individual effects and idiosyncratic components) as well as unknown future macroeconomic conditions (time effects). The simulation generates numerous pairs of the predicted income and consumption time series, which can be used to calculate the probabilities of the events of interest. It is assumed that the individual effects and idiosyncratic components follow normal distributions, and their values are randomly drawn from these distributions in the simulation.

As far as the macroeconomic environment is concerned, it is assumed that each future month is similar to one of the months in the training sample. This is especially true if the training sample covers a sufficiently long time period. Then the set of dummy variables control for the macroeconomic conditions that occur over the whole economic cycle. Thus, in the simulation, a time dummy is randomly selected for each future month (this would be replaced with drawing numbers from another normal distribution, if random time effects were used). The random selection of time 
dummies is a conservative approach that stems from the lack of knowledge of future macroeconomic conditions. If we have reliable macroeconomic forecasts, the randomly selected dummy variables can be replaced with a sequence of dummies that best describe the forecasted development of the macroeconomic situation.

Apart from the time dummies, the only time-variant regressors are age and changes in the number of children in different age groups. The latter can be calculated if the children's age is known at the time of application. It is assumed that the customer will not have more children in the loan repayment period. In each iteration of the simulation, the applicant's income and consumption are predicted over the repayment period that starts in month $A+1$, ie, the next month after the loan application is made, and lasts for $P$ months.

Each iteration comprises the following steps.

(1) The initial values are set as $\hat{Y}_{A}=Y_{A}$ and $\hat{C}_{A}=C_{A}$ (at the time of application).

(2) $M$ is randomly drawn from $N\left(0, \hat{\sigma}_{\mu}^{2}\right)$.

(3) $N$ is randomly drawn from $N\left(0, \hat{\sigma}_{v}^{2}\right)$.

(4) For each month $t+1=A+1, \ldots, A+P$ :

(a) $E_{t+1}$ is randomly drawn from $N\left(0, \hat{\sigma}_{\varepsilon}^{2}\right)$;

(b) $Z_{t+1}$ is randomly drawn from $N\left(0, \hat{\sigma}_{\zeta}^{2}\right)$;

(c) $S$ is randomly selected from among $1, \ldots, T$ (since $T$ is a reference category for the time dummies, it is assumed that $\hat{\gamma}_{T}=\hat{\delta}_{T}=0$ );

(d) the changes $\Delta \ln \hat{Y}_{t+1}$ and $\Delta \ln \hat{C}_{t+1}$ are predicted using the estimated models (the subscript $i$ is omitted, since the simulation is run for a given applicant)

$$
\begin{aligned}
\Delta \ln \hat{Y}_{t+1}= & \hat{\gamma}_{S}+\hat{\alpha}_{0}+\hat{\alpha}_{1} \text { age }_{t}+\hat{\alpha}_{2} \text { cohort }+\hat{\alpha}_{3} \text { sex }+\hat{\alpha}_{4} \text { education } \\
& +\hat{\alpha}_{5} \text { occupation }+\hat{\alpha}_{6} \text { sector }+\hat{\alpha}_{7} \text { region }+M+E_{t+1} \\
\Delta \ln \hat{C}_{t+1}=\hat{\delta}_{S} & +\hat{\beta}_{0}+\hat{\beta}_{1} \text { age }_{t}+\hat{\beta}_{2} \Delta \text { children }_{t+1}^{(0-3)} \\
& +\hat{\beta}_{3} \Delta \text { children }_{t+1}^{(4-15)}+\hat{\beta}_{4} \Delta \text { children }_{t+1}^{(16-19)} \\
& +N+Z_{t+1}
\end{aligned}
$$

and

(e) the predicted income and consumption $\hat{Y}_{t+1}$ and $\hat{C}_{t+1}$ are calculated as

$$
\begin{aligned}
& \hat{Y}_{t+1}=\exp \left(\ln \hat{Y}_{t}+\Delta \ln \hat{Y}_{t+1}\right), \\
& \hat{C}_{t+1}=\exp \left(\ln \hat{C}_{t}+\Delta \ln \hat{C}_{t+1}\right) .
\end{aligned}
$$


The above steps are repeated $N$ times; there are, for example, 1000 or, even better, 10000 iterations in the simulation. As a result, a large number of pairs of the predicted income and consumption time series are generated. They represent various possible paths of development of the customer's financial situation. For each of them, the ability to repay can be assessed. Thus, the simulation results are the input of the further analysis and form the basis of the dynamic affordability assessment. (Alternatively, we could estimate both models using an empirical Bayes approach with GLS estimates, or possibly fully Bayesian methods, to obtain predictive distributions of income and consumption; then a separate simulation would not be needed.)

The above-mentioned paths can be made even more realistic by taking into account other events that can affect the customer's income and consumption. For example, it can be assumed that the customer may lose their job with the probability $p_{\mathrm{u}}$. As long as they are employed, a number $u$ should be randomly drawn from a standard uniform distribution $U(0,1)$ in each step ( $4 \mathrm{e})$. If $u \leqslant p_{\mathrm{u}}$, it would be assumed that the customer has been made redundant and $\hat{Y}_{t+1}=0$. Similarly, it could be assumed that once they are unemployed they may find a job with the probability $p_{\mathrm{e}}$. Furthermore, we can draw a number from $U(0,1)$ in each step (4d) and compare it with the probability of the customer becoming a parent, to predict $\Delta$ children $_{t+1}^{(0-3)}$.

\subsection{Affordability check}

In this section, it is explained how the applicant's ability to repay is assessed for the $n$th pair of the predicted income and consumption time series $(n=1, \ldots, N)$ and a given installment amount $I$ of the new loan. Since the final result $D_{n}(I)$ of this assessment is binary (default or no default), it is referred to as an "affordability check". It is described with an example where a customer has a credit card and is applying for an installment loan. However, it can be adapted to any portfolio of credit cards and loans (including mortgages). The information on the applicant's debts can be obtained from credit reference agencies. Understandably, it is assumed that no other loans or credit cards will be granted to the customer in the loan repayment period.

\subsubsection{Order of payments}

For simplicity's sake, it is assumed that all transactions are made once a month: the customer gets their income, meets expenditure and makes other payments. They behave rationally and make optimal consumption choices. If there is enough money to meet all commitments, the order of payments does not matter. Otherwise, the order is important. Consumption costs are always covered first. Loan payments are made before credit card payments. Furthermore, loan arrears are settled before on-time installment payments, which is how lenders usually allocate money that comes into their account. Finally, the customer pays as much toward their credit card balance 
as they can after all other commitments are met (although this is not an obligatory payment).

To sum up, the following order of payments is assumed:

(1) consumption $\left(C_{t+1}\right)$,

(2) loan arrears $\left(A_{t+1}\right)$,

(3) loan installment $(I)$,

(4) credit card minimum payment $\left(\mathrm{MP}_{t+1}\right)$,

(5) credit card balance $\left(B_{t+1}\right)$.

Alternatively, the customer may prefer to make the credit card minimum payment before loan payments. Nevertheless, consumption, minimum payment, loan arrears and installment will be referred to as "obligatory payments":

$$
\mathrm{OP}_{t+1}=C_{t+1}+A_{t+1}+I+\mathrm{MP}_{t+1}
$$

If the customer has other loans and/or credit cards in their portfolio, they also need to be taken into account when calculating $\mathrm{OP}_{t+1}$. Obviously, there may be no arrears to pay, and if a credit card is not used, there is no minimum payment either. If the full credit card balance is paid, minimum payment is not required anymore.

\subsubsection{Making payments}

Each month the customer tries to meet all commitments (including the full credit card balance) out of income only. If this is not possible, they use both income and savings, and the latter are reduced afterward. If income and savings are not enough to make all obligatory payments and the allocated limit is at least partly available, the customer also uses a credit card. Naturally, this makes the credit card balance rise. Since all transactions are made once a month, the next month's initial balance is the final balance from a given month.

The customer makes as many payments as they can, according to the order of payments. If they cannot meet all commitments, the last one is likely to be only partly met (eg, a part of the installment may be unpaid). The unpaid installment or its part increases the loan arrears. The unpaid (part of) credit card interest increases the credit card balance. If minimum payments are missed or not fully made in three consecutive months, the credit card is suspended. Arrears, as well as savings, roll from month to month and can cumulate over time. 


\subsubsection{Saving}

If there is any money left after all commitments are met (including the full credit card balance being paid), savings $S_{t+1}$ are generated according to the following formula:

$$
S_{t+1}=S_{t}+p\left(Y_{t}-C_{t}-A_{t}-I-B_{t}\right) .
$$

It is assumed that a fraction $p$ of the money left is saved and $1-p$ is spent, for example, on durable consumption. If $p=0$, saving is not allowed. If $p=1$, all the money is saved. This money can be used later when needed, since repaying a loan out of savings is still considered by the OFT as meeting repayments "in a sustainable manner" (Office of Fair Trading 2011, Paragraph 4.3).

\subsubsection{Reducing consumption}

If the customer cannot make all obligatory payments in a given month $t+1$, they may reduce their consumption by a small fraction $q$ so that $C_{t+1}^{*}=(1-q) C_{t+1}$ (if $q=0$, reducing consumption is not allowed). If an even smaller reduction is enough, then $(1-q) C_{t+1}<C_{t+1}^{*}<C_{t+1}$. This results in new obligatory payments

$$
\mathrm{OP}_{t+1}^{*}=C_{t+1}^{*}+A_{t+1}+I+\mathrm{MP}_{t+1} .
$$

Since $C_{t+1}^{*}$ is not the consumer's optimal choice, it is not used to calculate the estimated consumption in the next month. It is commonly known that those on lower incomes spend proportionally more on essential consumption than those on higher incomes, and essential consumption is much more difficult to reduce than quality of life consumption. Therefore, different values of $q$ could be used, depending on the customer's income level.

Although limiting expenditure in an attempt to avoid missing payments seems a very likely scenario, we can ask whether the loan is still affordable when a customer is forced to reduce their consumption to meet other commitments. For example, if a consumer has to give up 5\% of their expenditure, can they still afford "normal/reasonable outgoings" as the OFT expects (Office of Fair Trading 2011, Paragraph 4.4)? The answer is up to a potential user of this approach to decide.

\subsubsection{Failing to pay and defaulting}

It is assumed that the customer fails to pay in a given month if they cannot make all obligatory payments even after a consumption reduction:

$$
Y_{t+1}+S_{t+1}+L_{t+1}<\mathrm{OP}_{t+1}^{*},
$$

where $L_{t+1}$ is the available credit limit. If they fail to pay in three consecutive months, they default and $D_{n}(I)=1$; otherwise $D_{n}(I)=0$. This definition is similar to those 
used by credit reference agencies in that it does not matter on which loan/credit the default occurs. In this respect, it is in line with the OFT recommendations, which state that a customer should be able to make other debt repayments as well (Office of Fair Trading 2011, Paragraph 4.4). However, it is also possible to analyze only failures and defaults on the new loan.

\subsubsection{Miscellaneous}

In order to avoid modeling inflation rate, it is assumed that income and consumption are expressed in the pounds of the application time. A similar assumption was adopted, for example, by Lillard and Willis (1978). It is also assumed that the customer can neither lend nor invest their money, and cannot realize assets, such as properties, to make payments. According to the OFT, having to realize assets means that the loan is not repaid "in a sustainable manner" (Office of Fair Trading 2011, Paragraph 4.3).

\subsection{Affordability assessment}

The dynamic affordability assessment is based on affordability checks for all pairs of the predicted income and consumption time series that have been generated in the simulation. For each pair of time series there is a prediction of whether and in which month(s) the customer will fail to pay or default. Since there are a large number of such pairs, a proportion of those, where defaults are predicted to occur, can be an estimate of probability of default over the loan repayment period. Probability of failure can be estimated in a similar way. Probabilities of default and failure can be calculated not only for the whole repayment period, but also for shorter periods such as the first year of repayment. However, all these probabilities are only for a given installment amount.

As far as affordability is concerned, Thomas (2009) suggested that the probability of the customer being "good" or "bad" may be a function of the interest rate charged on the loan. In this research, affordability is measured by a function $A(x)$ that assigns to each possible installment amount $x \in X$ a probability of the applicant defaulting as a result of their inability to repay over the loan repayment period. (It seems convenient to express $A$ in terms of the probabilities of default, but a potential user of this approach may prefer to use the complement probabilities, $1-A(x)$, to measure affordability.) Understandably, $A$ is monotonically increasing. It is continuous but can be approximated by a discrete function. In order to estimate this function, affordability checks for all pairs of time series need to be repeated for all possible installment amounts ( $£ 500, £ 501, £ 502, \ldots, £ 1000$, for example):

$$
A(x)=\frac{1}{N} \sum_{n=1}^{N} D_{n}(x), \quad \forall x \in X .
$$


Similarly, we can estimate a function that assigns a probability of failure instead of a probability of default. Nevertheless, in this research, affordability is linked to the latter, since according to the OFT a loan can be considered as being repaid "in a sustainable manner" even despite occasional failure to pay (Office of Fair Trading 2011, Paragraph 4.7).

Once affordability is assessed, we can find the maximum affordable installment (MAI) that corresponds to the maximum affordable loan for the applicant by taking the last amount that is associated with acceptable probability of default. Therefore, MAI can be identified as the highest possible installment amount $x \in X$ for which affordability is less than or equal to the cutoff (5\% for the sake of the example, or any other value that is deemed appropriate):

$$
\mathrm{MAI}=\max \{x \in X: A(x) \leqslant 0.05\} .
$$

Alternatively, we can take the last amount before a sharp increase in probability of default. Thus, MAI can be determined as the highest reasonable installment amount $x \in X_{\mathrm{R}}$ for which marginal affordability does not exceed the threshold $(0.1 \%$, for example):

$$
\mathrm{MAI}=\max \left\{x \in X_{\mathrm{R}}: A^{\prime}(x) \leqslant 0.001\right\},
$$

where $A^{\prime}$ is the derivative of $A$ with respect to $x$ and $X_{\mathrm{R}} \subset X$ (the estimated function is likely to be $S$-shaped and, after the sharp increase, marginal affordability can become low again but for high, unreasonable amounts).

If we are interested in identifying the maximum affordable installment rather than assessing affordability, it is possible to use the bisection method to reduce the computation time. When, for example, the cutoff is set to $5 \%$, the algorithm works as follows.

(1) The initial values are set as $x_{\mathrm{L}}=\min \{X\}$ and $x_{\mathrm{U}}=\max \{X\}$.

(2) The following steps are repeated until convergence is reached:

(a) the midpoint is calculated as $x_{\mathrm{M}}=\left[\left(x_{\mathrm{L}}+x_{\mathrm{U}}\right) / 2\right]$;

(b) if $A\left(x_{\mathrm{M}}\right) \leqslant 0.05$, then $x_{\mathrm{L}}=x_{\mathrm{M}}$;

(c) if $A\left(x_{\mathrm{M}}\right) \geqslant 0.05$, then $x_{\mathrm{U}}=x_{\mathrm{M}}$.

(3) The maximum affordable installment is determined as MAI $=x_{\mathrm{M}}$.

It has been assumed that, as long as all obligatory payments are made, the loan is still repaid "in a sustainable manner" and is thus affordable, even if the customer occasionally needs to use a credit card to cover part of their consumption costs. However, the maximum affordable installment could be redefined in a more conservative way. 
For example, we could take the highest amount such that the customer will avoid default without the need to use a credit card in the loan repayment period with at least $95 \%$ probability. Obviously, the resulting installment amounts will be generally lower.

We would argue that the dynamic affordability assessment is in line with recommendations of the OFT and FSA. First, the applicant's ability to repay is assessed over the life of the loan. Second, possible future changes in their income and expenditure are taken into account. Finally, in this approach, a loan is affordable if the applicant is able to repay it while also meeting consumption costs and repayments of all other debts month after month until the loan is paid in full.

\section{EXAMPLE}

\subsection{Assumptions}

The dynamic affordability assessment is illustrated with an example based on artificial data. In this example, a hypothetical forty-five-year-old childless man is applying for an installment loan with a two-year (twenty-four month) repayment period. What needs to be determined is the maximum affordable installment. At the time of application, the customer's net income and expenditure are equal to $£ 2300$ and $£ 1500$, respectively. He has a credit card with a limit of $£ 1000$. The minimum payment is the greater of interest plus $1 \%$ of the credit card balance and $£ 5$ (or the full balance if it is less than £5). The monthly interest rate is fixed at $1.5 \%$. There are no default fees/charges if an installment is missed or the minimum payment is not paid on time (though such fees and charges can be easily introduced). In the first month of the loan repayment period, the customer has no savings that could help him meet commitments, but the full credit card limit is available. The latter assumptions can be modified according to the lender's knowledge by adopting some initial values of savings and/or the credit card balance.

It is assumed that the income and consumption change models have been built on a five-year (sixty-month) training sample so that there are fifty-nine time dummies. As a result, there are some estimates of the model parameters as well as variances of the individual effects and the idiosyncratic components (see Table 2 on the next page). In the absence of available data, their values have been chosen arbitrarily here and for illustrative purposes only. Where possible, the estimates which had been obtained in other studies have been assumed. For example, $\hat{\beta}_{1}$ is similar to the estimate of the effect of age reported by Jappelli and Pistaferri (2000), corrected for the difference in units (months versus years). The ratio $\hat{\beta}_{2}: \hat{\beta}_{3}: \hat{\beta}_{4}$ is equal to the ratio of the individual food standards for children of the three age groups (see Zeldes 1989). On the basis of the assumed estimates, the simulation has been run for the above-mentioned hypothetical applicant. The simulation consisted of 10000 iterations. 
TABLE 2 Assumed estimates.

(a) Income change model

\begin{tabular}{lc}
\hline \multicolumn{1}{c}{ Estimates } & Values \\
\hline$\hat{\gamma}_{1}, \ldots, \hat{\gamma}_{59}$ & From -0.0015 to 0.0015 \\
$\hat{\alpha}_{0}$ & 0.001 \\
$\hat{\alpha}_{1}$ & 0.000005 \\
$\hat{\alpha}_{2}$ cohort $+\hat{\alpha}_{3}$ sex & 0.0001 \\
$+\hat{\alpha}_{4}$ education $+\hat{\alpha}_{5}$ occupation & (A value of the whole \\
$+\hat{\alpha}_{6}$ sector $+\hat{\alpha}_{7}$ region & expression for the applicant) \\
Individual effect variance $\hat{\sigma}_{\mu}^{2}$ & 0.002 \\
Idiosyncratic component variance $\hat{\sigma}_{\varepsilon}^{2}$ & 0.003 \\
\hline
\end{tabular}

(b) Consumption change model

\begin{tabular}{lc}
\hline \multicolumn{1}{c}{ Estimates } & Values \\
\hline$\hat{\delta}_{1}, \ldots, \hat{\delta}_{59}$ & From -0.003 to 0.003 \\
$\hat{\beta}_{0}$ & 0.002 \\
$\hat{\beta}_{1}$ & 0.000005 \\
$\hat{\beta}_{2}$ & 0.002 \\
$\hat{\beta}_{3}$ & 0.003 \\
$\hat{\beta}_{4}$ & 0.004 \\
Individual effect variance $\hat{\sigma}_{v}^{2}$ & 0.0025 \\
Idiosyncratic component variance $\hat{\sigma}_{\zeta}^{2}$ & 0.0035 \\
\hline
\end{tabular}

When assessing affordability, several variants of assumptions have been considered. In the basic variant, all the money left is saved ( $p=1)$, reducing consumption is not allowed $(q=0)$ and the customer meets commitments according to the order of payments. In the other variants:

(1) only half of the money left can be saved ( $p=0.5)$;

(2) saving is not allowed $(p=0)$;

(3) consumption can be reduced by up to $5 \%(q=0.05)$;

(4) consumption can be reduced by up to $10 \%(q=0.1)$;

(5) the alternative order of payments is assumed (the credit card minimum payment is made before the loan payments).

The results obtained for different variants of assumptions are compared. 
TABLE 3 Probabilities of default for different variants of assumptions.

\begin{tabular}{cccccc}
\hline $\begin{array}{c}\text { Installment } \\
\text { amount (£) }\end{array}$ & Basic variant & $\boldsymbol{p}=\mathbf{0 . 5}$ & $\boldsymbol{p}=\mathbf{0}$ & $\boldsymbol{q}=\mathbf{0 . 0 5}$ & $\boldsymbol{q}=\mathbf{0 . 1}$ \\
\hline 400 & 0.0000 & 0.0000 & 0.0000 & 0.0000 & 0.0000 \\
450 & 0.0000 & 0.0000 & 0.0001 & 0.0000 & 0.0000 \\
500 & 0.0000 & 0.0001 & 0.0001 & 0.0000 & 0.0000 \\
550 & 0.0001 & 0.0001 & 0.0006 & 0.0001 & 0.0001 \\
600 & 0.0005 & 0.0006 & 0.0022 & 0.0004 & 0.0003 \\
650 & 0.0020 & 0.0042 & 0.0093 & 0.0020 & 0.0018 \\
700 & 0.0164 & 0.0238 & 0.0336 & 0.0132 & 0.0113 \\
750 & 0.0739 & 0.0817 & 0.0895 & 0.0681 & 0.0435 \\
800 & 0.2201 & 0.2206 & 0.2212 & 0.2008 & 0.0906 \\
850 & 0.4604 & 0.4604 & 0.4604 & 0.3687 & 0.1695 \\
900 & 0.7278 & 0.7278 & 0.7278 & 0.5713 & 0.2872 \\
950 & 0.9314 & 0.9314 & 0.9314 & 0.8295 & 0.4914 \\
1000 & 0.9959 & 0.9959 & 0.9959 & 0.9743 & 0.8022 \\
1050 & 0.9999 & 0.9999 & 0.9999 & 0.9992 & 0.9762 \\
1100 & 1.0000 & 1.0000 & 1.0000 & 0.9999 & 0.9996 \\
1150 & 1.0000 & 1.0000 & 1.0000 & 1.0000 & 0.9999 \\
1200 & 1.0000 & 1.0000 & 1.0000 & 1.0000 & 1.0000 \\
\hline
\end{tabular}

\subsection{Results}

The simulation generated 10000 pairs of the predicted income and consumption time series that cover the two-year repayment period. In the last month of this period, the average predicted income is equal to around $£ 2526$, which corresponds to an annual increase of $4.80 \%$. In the same month, the average predicted consumption is equal to around $£ 1684$, which corresponds to an annual increase of $5.95 \%$. On average, the applicant's consumption is predicted to grow a bit faster than his income.

At the time of application, the customer's disposable income equals $£ 2300-$ $£ 1500=£ 800$. For illustrative purposes, possible installment amounts ranging from $£ 300$ to $£ 1300$ (ie, $£ 800 \pm £ 500$ ) were analyzed. In practice, though, a narrower range would be sufficient. Probabilities of default for selected amounts are presented in Table 3. They can be interpreted as follows. For example, in the basic variant, if the new installment is equal to $£ 750$, the probability that the applicant will default in the repayment period is 0.0739 (around 7\%). Unsurprisingly, if there are limits on saving, probabilities of default are higher (but only for amounts that do not exceed $£ 817$, since being able to repay higher amounts depends very little on savings). If consumption can be reduced, the probabilities are lower for all amounts. Allowing a 
TABLE 4 Maximum affordable installments for different variants of assumptions.

\begin{tabular}{|c|c|c|c|c|c|}
\hline $\begin{array}{c}\text { Cutoff } \\
\text { (probability } \\
\text { of default) }\end{array}$ & $\begin{array}{c}\text { Basic } \\
\text { variant } \\
(£)\end{array}$ & $\begin{array}{c}p=0.5 \\
(£)\end{array}$ & $\begin{array}{c}p=0 \\
(£)\end{array}$ & $q=0.05$ & $\begin{array}{c}q=0.1 \\
(£)\end{array}$ \\
\hline 0.05 & 735 & 730 & 721 & 739 & 758 \\
\hline 0.06 & 742 & 737 & 728 & 745 & 768 \\
\hline 0.07 & 747 & 743 & 736 & 751 & 779 \\
\hline 0.08 & 752 & 749 & 743 & 756 & 790 \\
\hline 0.09 & 757 & 754 & 750 & 761 & 799 \\
\hline 0.10 & 762 & 759 & 755 & 765 & 808 \\
\hline
\end{tabular}

reduction of up to $10 \%$ results in probabilities of default that are much lower than in the basic variant. However, this assumption may be considered a step too far.

The results which were obtained for the alternative order of payments are almost identical to those for the basic variant and thus are not reported in this paper. As far as defaults are concerned, the order of payments hardly makes any difference. The alternative order of payments led to some additional defaults but only in around 650 out of 10000000 affordability checks (10000 simulation iterations $\times 1000$ possible installment amounts).

Regardless of the assumptions, if the new installment is less than or equal to $£ 414$, the probability that the applicant will default is zero, which seems to be unlikely in reality. The reason for this is twofold. First, there are no income shocks such as unemployment in the simulation, and thus it is always possible for the customer to repay some amount. Second, this is just the probability of default as a result of the customer's inability to repay, whereas defaults may have other causes (eg, a lack of intention to pay).

The maximum affordable installments for several reasonable cutoffs are demonstrated in Table 4. In the basic variant, the maximum new installment for which probability of default does not exceed $5 \%$ is equal to $£ 735$. When the cutoff is set to $10 \%$, MAI equals $£ 762$. As expected, if only one-half or none of the money left can be saved, the amounts are lower, and if reducing consumption is allowed, they are higher. Nevertheless, for each reasonable cutoff, the results are quite similar, except for those for the variant where consumption can be reduced by up to $10 \%$. This shows that the proposed approach may be relatively robust to the assumptions.

Instead of using such cutoffs as in Table 4, we can take the last amount before a relatively sharp rise in probability of default. When the threshold is $0.1 \%$ in the basic variant, MAI equals $£ 732$ : within the range of reasonable amounts, every pound above $£ 732$ increases probability of default by more than 0.001 (ie, 0.1 percentage point). We can think of this increase as marginal affordability. 
TABLE 5 Probabilities of failure for selected amounts and different variants of assumptions.

\begin{tabular}{cccccc}
\hline $\begin{array}{c}\text { Installment } \\
\text { amount }(\boldsymbol{\Sigma})\end{array}$ & Basic variant & $\boldsymbol{p}=\mathbf{0 . 5}$ & $\boldsymbol{p}=\mathbf{0}$ & $\boldsymbol{q}=\mathbf{0 . 0 5}$ & $\boldsymbol{q}=\mathbf{0 . 1}$ \\
\hline 400 & 0.0000 & 0.0000 & 0.0001 & 0.0000 & 0.0000 \\
450 & 0.0000 & 0.0000 & 0.0001 & 0.0000 & 0.0000 \\
500 & 0.0000 & 0.0001 & 0.0006 & 0.0000 & 0.0000 \\
550 & 0.0001 & 0.0005 & 0.0018 & 0.0001 & 0.0001 \\
600 & 0.0006 & 0.0019 & 0.0060 & 0.0006 & 0.0006 \\
650 & 0.0049 & 0.0086 & 0.0188 & 0.0042 & 0.0035 \\
700 & 0.0286 & 0.0362 & 0.0477 & 0.0256 & 0.0216 \\
750 & 0.0963 & 0.1034 & 0.1154 & 0.0893 & 0.0575 \\
800 & 0.2477 & 0.2487 & 0.2498 & 0.2257 & 0.1062 \\
850 & 0.4771 & 0.4771 & 0.4771 & 0.3885 & 0.1886 \\
900 & 0.7310 & 0.7310 & 0.7310 & 0.5993 & 0.3073 \\
950 & 0.9341 & 0.9341 & 0.9341 & 0.8553 & 0.5285 \\
1000 & 0.9962 & 0.9962 & 0.9962 & 0.9851 & 0.8520 \\
1050 & 0.9999 & 0.9999 & 0.9999 & 0.9998 & 0.9913 \\
1100 & 1.0000 & 1.0000 & 1.0000 & 1.0000 & 0.9998 \\
1150 & 1.0000 & 1.0000 & 1.0000 & 1.0000 & 1.0000 \\
1200 & 1.0000 & 1.0000 & 1.0000 & 1.0000 & 1.0000 \\
\hline
\end{tabular}

TABLE 6 Maximum installment amounts for different variants of assumptions.

\begin{tabular}{cccccc}
\hline $\begin{array}{c}\text { Cutoff } \\
\text { (probability } \\
\text { of failure) }\end{array}$ & $\begin{array}{c}\text { Basic } \\
\text { variant } \\
\mathbf{( \Sigma )}\end{array}$ & $\begin{array}{c}\boldsymbol{p}=\mathbf{0 . 5} \\
\mathbf{( \Sigma )}\end{array}$ & $\begin{array}{c}\boldsymbol{p}=\mathbf{0} \\
\mathbf{( \Sigma )}\end{array}$ & $\begin{array}{c}\boldsymbol{q}=\mathbf{0 . 0 5} \\
\mathbf{( £ )}\end{array}$ & $\begin{array}{c}\boldsymbol{q}=\mathbf{0 . 1} \\
\mathbf{( \Sigma )}\end{array}$ \\
\hline 0.05 & 723 & 715 & 702 & 726 & 741 \\
0.06 & 729 & 722 & 710 & 733 & 752 \\
0.07 & 736 & 729 & 719 & 739 & 764 \\
0.08 & 741 & 736 & 727 & 744 & 775 \\
0.09 & 747 & 742 & 735 & 750 & 785 \\
0.10 & 751 & 748 & 742 & 754 & 795 \\
\hline
\end{tabular}

The above analysis has linked affordability to probability of default. For comparison purposes, a similar analysis was performed for failures instead of defaults (a failure is defined here as the inability to make all obligatory payments in one or more months). Obviously, the probabilities obtained are higher and the maximum installment amounts are lower (see Tables 5 and 6). In the basic variant, if the new installment is equal to $£ 750$, the probability of failure in the repayment period is 0.0963 (around $10 \%$ compared with around $7 \%$ probability of default). When the cutoff is set to $5 \%$, 
the maximum new installment equals $£ 723$ (compared with $£ 735$ ). When the cutoff is $10 \%$, the amount is equal to $£ 751$ (compared with $£ 762$ ). The results of this analysis for the alternative order of payments are exactly the same as those for the basic variant, since the order of payments does not matter until the customer fails to pay.

\section{DISCUSSION}

In order to apply this theoretical framework in practice, we would need monthly panel data on income and expenditure at least for a few thousand consumers whose characteristics, such as age, are known. The data that is needed to develop the proposed models should cover several years (ideally around seven years, ie, the whole economic cycle). There are two possible sources of such data: surveys and current account transactions (Thomas 2009; Maydon 2011). As far as the latter is concerned, Thomas (2009) suggested that the total value of credits can be an estimate of the consumer's income, whereas the total value of debits can be an estimate of their expenditure in a given month. If this is applied, the models could be said to be at the account level. Suitable panel surveys may be difficult to obtain, but transaction data is available in each bank and also for some credit reference agencies, such as Experian, which uses Current Account Turnover (CATO) data provided by UK banks (Experian 2011). There is no need to use data on the consumers' debts to build the models, but such data from a credit report is needed later to perform affordability checks in order to assess affordability.

The models should be separately tested/validated on a hold-out sample. The whole approach could be validated by analyzing only probabilities of default assigned to those installment amounts that were actually agreed. It seems that there should be no reject inference problem, since the models would be developed on a sample of all customers whose income and consumption history is known (not only those who applied for a loan and were accepted by the lender). The analyzed probabilities can be matched with the customers' performance over the loan repayment periods (default on any loan/credit card or no default). Subsequently, the calibration and discriminatory power of the whole approach can be validated as normal in credit scoring (Thomas 2009).

\section{CONCLUSIONS}

The OFT and FSA recommend taking into account dynamic aspects of affordability. In this paper, a theoretical framework for dynamic affordability assessment was proposed. Income and consumption change models were suggested on the basis of the economic literature. The models were used in a simulation to estimate affordability, which is measured by a function that assigns to each possible installment amount the 
probability of the applicant defaulting over the loan repayment period. This allows for the identification of the maximum affordable installment (two identification methods were suggested). The dynamic affordability assessment was demonstrated on an example based on artificial data. The results suggest that it may be relatively robust to the assumptions on saving and reducing consumption. Interestingly, almost identical results were obtained for different orders of payments. We believe that the dynamic affordability assessment is in line with recommendations of the OFT and FSA. It also offers significant advantages over the static approach, such as taking a long-term perspective and considering the dynamic nature of the customer's financial situation.

The proposed approach could help determine the maximum affordable loan for the applicant. In the simulation and when assessing affordability, however, many other results are produced. We can analyze probabilities of default and failure over any time period (eg, the first six or twelve months) and construct some sort of "survival functions". For a given installment amount, we can derive distributions of loan arrears, credit card arrears, credit card balance, savings, etc, in any month (there are as many predicted time series of each of these quantities as there are affordability checks for the analyzed installment amount). It is also possible to compute a distribution of exposure at default for the new loan.

With appropriate samples, the proposed approach could be applied and tested on real-life data. Since the output of this research is a theoretical framework, there is also plenty of room for further modifications. For example, we could use a more sophisticated version of the Euler equation by including liquidity constraints or precautionary saving. Under the assumption of liquidity constraints, optimal consumption might have been higher if the consumer had been able to borrow more. When precautionary saving is allowed, consumption can be reduced to set aside savings in the presence of uncertainty about the future.

Moreover, in the simulation, we could introduce permanent and transitory income shocks that may occur with very low probability. Income shocks can be both positive (eg, promotion) and negative (eg, unemployment) but, at least according to the $\mathrm{PIH}$, consumption is sensitive only to permanent shocks. This could make the simulation even more realistic, although the OFT does not require the possibility of the applicant being made redundant in the future to be taken into account (Office of Fair Trading 2011, Paragraph 4.10). However, the OFT does expect lenders to take into account future changes in the customer's personal circumstances such as retirement (Office of Fair Trading 2011, Paragraph 4.10). We could consider other changes that can affect income and/or consumption, such as having (more) children. The probabilities of becoming a parent can be easily obtained for all sex and age groups, and could be incorporated into the simulation. Nevertheless, the above suggestions do not exhaust the possibilities of modifying the theoretical framework for dynamic affordability assessment proposed in this paper. 


\section{REFERENCES}

Anderson, R. (2007). The Credit Scoring Toolkit. Oxford University Press.

Association for Payment Clearing Services, British Bankers' Association, Building Societies Association et al (2000). Guide to Credit Scoring. Available at www.bba.org.uk/ wp-content/uploads/2007/08/Guide_to_Credit_Scoring_2000-1.pdf (accessed March 3, 2014).

Auten, G., and Carroll, R. (1999). The effect of income taxes on household income. Review of Economics and Statistics 81(4), 681-693.

Balestra, P., and Nerlove, M. (1966). Pooling cross section and time series data in the estimation of a dynamic model: the demand for natural gas. Econometrica 34(3), 585612.

Betti, G., Dourmashkin, N., Rossi, M. C., Verma, V., and Yin, Y. (2001). Study of the problem of consumer indebtedness: statistical aspects. A report to the Commission of the European Communities Directorate-General for Health and Consumer Protection.

British Bankers' Association, Building Societies Association, and the UK Cards Association (2011). The lending code: setting standards for banks, building societies and credit card providers.

Brooksby, B. (2009). Measuring affordability at origination. In Credit Scoring and Credit Control XI, Edinburgh. Conference Archive. Available at www.business-school.ed.ac.uk/ $\mathrm{crc/conferences/conference-archive?a=45896} \mathrm{(accessed} \mathrm{March} \mathrm{3,} \mathrm{2014).}$

Bryan, M., Taylor, M., and Veliziotis, M. (2010). Over-indebtedness in Great Britain: an analysis using the wealth and assets survey and household annual debtors survey. Report to the Department for Business, Innovation and Skills.

Consumer Credit Act (2006). Chapter 14. The Stationery Office, London.

Crook, J., and Bellotti, T. (2008). Dynamic consumer risk models: an overview. In Dynamic Consumer Risk Modelling and the Economy, Edinburgh. Conference Archive. Available at www.business-school.ed.ac.uk/crc/conferences/conference-archive?a $=45827$ (accessed March 3, 2014).

Dell, D. D. (2007). Making affordability work for you! In Credit Scoring and Credit Control X, Edinburgh. Conference Archive. Available at www.business-school.ed.ac.uk/crc/ conferences/conference-archive? $\mathrm{a}=45502$ (accessed March 3, 2014).

Department of Trade and Industry (2005). Over-indebtedness in Britain: a DTI report on the MORI Financial Services survey 2004.

Disney, R., Bridges, S., and Gathergood, J. (2008). Drivers of overindebtedness. Report to the Department for Business, Enterprise and Regulatory Reform.

Etienne, J.-M. (2006). Health and socio-economic status: is it measured income or permanent income that matters? In XX Annual Conference of the European Society for Population Economics, Verona. Conference Proceedings. Available at http://dse.univr.it/ espe/documents/Papers/C/6/C6_4.pdf (accessed March 3, 2014).

European Parliament and Council of the European Union (2008). Directive 2008/48/EC of 23 April 2008 on credit agreements for consumers and repealing Council Directive 87/102/EEC. Official Journal of the European Union L133/66.

Experian (2011). The affordability challenge. Briefing Paper, Experian, Nottingham.

Financial Services Authority (2009). Mortgage market review. Discussion Paper 09/3, FSA, London. 
Financial Services Authority (2010). Mortgage market review: responsible lending. Consultation Paper 10/16, FSA, London.

Finlay, S. M. (2006). Predictive models of expenditure and over-indebtedness for assessing the affordability of new consumer credit applications. Journal of the Operational Research Society 57(6), 655-669.

Fondeville, N., Özdemir, E., and Ward, T. (2010). Over-indebtedness: new evidence from the EU-SILC special module. Research Note 4/2010 for the European Commission Directorate-General for Employment, Social Affairs and Equal Opportunities. Available at http://ec.europa.eu/social/BlobServlet?docld=6708\&langld=en (accessed March 3, 2014).

Friedman, M. (1957). A Theory of the Consumption Function. Princeton University Press.

Greene, W. H. (2000). Econometric Analysis, 4th edn. Prentice Hall, Upper Saddle River, NJ.

Guiso, L., Jappelli, T., and Terlizzese, D. (1992). Earnings uncertainty and precautionary saving. Journal of Monetary Economics 30(2), 307-337.

Hall, R. E. (1978). Stochastic implications of the life cycle-permanent income hypothesis: theory and evidence. Journal of Political Economy 86(6), 971-987.

Hall, R. E., and Mishkin, F. S. (1982). The sensitivity of consumption to transitory income: estimates from panel data on households. Econometrica 50(2), 461-481.

Jappelli, T., and Pistaferri, L. (2000). Using subjective income expectations to test for excess sensitivity of consumption to predicted income growth. European Economic Review 44(2), 337-358.

Jappelli, T., and Pistaferri, L. (2006). Intertemporal choice and consumption mobility. Journal of the European Economic Association 4(1), 75-115.

Kempson, E. (2002). Over-indebtedness in Britain. A report to the Department of Trade and Industry.

Koskinen, L., Nummi, T., and Salonen, J. (2007). Modeling and predicting individual salaries: a study of Finland's unique dataset. In Second Colloquium of the Pensions, Benefits and Social Security (PBSS) Section of the International Actuarial Association (IAA), Helsinki. Available at www.actuaries.org/PBSS/Colloquia/Helsinki/Papers/Koskinen.pdf (accessed March 3, 2014).

Lillard, L. A., and Willis, R. J. (1978). Dynamic aspects of earning mobility. Econometrica 46(5), 985-1012.

Lucas, R. (2005). Improving credit offers using affordability predictions. In Credit Scoring and Credit Control IX, Edinburgh. Conference Archive. Available at www.business-school .ed.ac.uk/crc/conferences/conference-archive?a=45618 (accessed March 3, 2014).

Lucas, R. E., Jr. (1976). Econometric policy evaluation: a critique. In The Phillips Curve and Labor Markets, Brunner, K., and Meltzer, A. H. (eds). Carnegie-Rochester Conference Series on Public Policy, pp. 19-46. North-Holland, Amsterdam.

Lusardi, A. (1992). Permanent income, current income and consumption: evidence from panel data. Center for Economic Research Discussion Paper 9253, Tilburg University.

Maddala, G. S. (2001). Introduction to Econometrics, 3rd edn. Wiley.

Maydon, T. (2011). The evolution of customer affordability determination in the South African market. In Credit Scoring and Credit Control XII, Edinburgh. Conference Archive. Available at www.business-school.ed.ac.uk/crc/conferences/conference-archi ve?a=46024 (accessed March 3, 2014). 
Miles, D. (1997). A household level study of the determinants of incomes and consumption. Economic Journal 107(440), 1-25.

Modigliani, F., and Brumberg, R. (1954). Utility analysis and the consumption function: an interpretation of cross-section data. In Post Keynesian Economics, Kurihara, K. K. (ed), pp. 388-436. Rutgers University Press, New Brunswick, NJ.

Office of Fair Trading (2011). Irresponsible lending: OFT guidance for creditors. OFT, London.

Oxera (2004). Are UK households over-indebted? Report prepared for the Association for Payment Clearing Services, British Bankers' Association, Consumer Credit Association and Finance and Leasing Association.

Runkle, D. E. (1991). Liquidity constraints and the permanent-income hypothesis: evidence from panel data. Journal of Monetary Economics 27(1), 73-98.

Russell, P. (2005). Over-indebtedness and responsible lending in the UK. In Credit Scoring and Credit Control IX, Edinburgh. Conference Archive. Available at www.business-school .ed.ac.uk/crc/conferences/conference-archive?a=45630 (accessed March 3, 2014).

Snowdon, B., and Vane, H. R. (2005). Modern Macroeconomics: Its Origins, Development and Current State. Edward Elgar, Cheltenham.

Somers, M. (2009). Credit card initial limits: how much is too much? In Credit Scoring and Credit Control XI, Edinburgh. Conference Archive. Available at www.business-school.ed .ac.uk/crc/conferences/conference-archive?a=45908 (accessed March 3, 2014).

Thomas, L. C. (2009). Consumer Credit Models: Pricing, Profit, and Portfolios. Oxford University Press.

Thomas, L. C. (2011). Credit scoring and the Edinburgh Conference: Fringe or International Festival. In Credit Scoring and Credit Control XII, Edinburgh. Conference Archive. Available at www.business-school.ed.ac.uk/crc/conferences/conference-archive $? \mathrm{a}=46084$ (accessed March 3, 2014).

UK Cards Association, The (2011). Credit card limit increases. Report, London.

Verbeek, M. (2004). A Guide to Modern Econometrics, 2nd edn. Wiley.

Wilkinson, G. (2007). Responsible lending. In Credit Scoring and Credit Control X, Edinburgh. Conference Archive. Available at www.business-school.ed.ac.uk/crc/conferenc es/conference-archive?a=45511 (accessed March 3, 2014).

Wooldridge, J. M. (2010). Econometric Analysis of Cross Section and Panel Data, 2nd edn. MIT Press, Cambridge, MA.

Zeldes, S. P. (1989). Consumption and liquidity constraints: an empirical investigation. Journal of Political Economy 97(2), 305-346. 